\title{
Dietary Quality in Vegetarian and Omnivorous Female Students in Germany: A Retrospective Study
}

\author{
Julia Blaurock ${ }^{1}\left(\mathbb{D}\right.$, Birgit Kaiser ${ }^{1}$, Tamara Stelz1 ${ }^{2}{ }^{\oplus}$, Michelle Weech $^{3}$, Rosalind Fallaize ${ }^{3}$, Rodrigo Zenun Franco ${ }^{4}$, \\ Faustina Hwang ${ }^{5}$, Julie Lovegrove ${ }^{3} \mathbb{D}$, Paul M. Finglas ${ }^{6} \mathbb{D}$ and Kurt Gedrich $1, * \mathbb{D}$ \\ 1 ZIEL-Institute for Food \& Health, Technical University of Munich, 85354 Freising, Germany; \\ julia.blaurock@tum.de (J.B.); birgit.kaiser@tum.de (B.K.) \\ 2 Analytical Food Chemistry, Technical University of Munich, 85354 Freising, Germany; tamara.stelzl@tum.de \\ 3 Hugh Sinclair Unit of Human Nutrition, Department of Food and Nutritional Sciences, University of Reading, \\ Reading RG6 6DZ, UK; m.weech@reading.ac.uk (M.W.); r.fallaize@reading.ac.uk (R.F.); \\ j.a.lovegrove@reading.ac.uk (J.L.) \\ 4 Globalyze, Virgílio Malta 17-76, 17014-440 Bauru, Brazil; rodrigo@globalyze.work \\ 5 Biomedical Engineering, School of Biological Sciences, University of Reading, Reading RG6 6DH, UK; \\ f.hwang@reading.ac.uk \\ 6 Quadram Bioscience Institute, Norwich NR4 7UQ, UK; paul.finglas@quadram.ac.uk \\ * Correspondence: kgedrich@tum.de; Tel.: +49-816-171-2483; Fax: +49-816-171-5029
}

check for updates

Citation: Blaurock, J.; Kaiser, B.; Stelzl, T.; Weech, M.; Fallaize, R.; Franco, R.Z.; Hwang, F.; Lovegrove, J.; Finglas, P.M.; Gedrich, K. Dietary Quality in Vegetarian and Omnivorous Female Students in Germany: A Retrospective Study. Int. J. Environ. Res. Public Health 2021, 18, 1888. https://doi.org/10.3390/ijerph 18041888

Academic Editor: Paul B. Tchounwou Received: 24 January 2021

Accepted: 11 February 2021

Published: 16 February 2021

Publisher's Note: MDPI stays neutral with regard to jurisdictional claims in published maps and institutional affiliations.

Copyright: (c) 2021 by the authors. Licensee MDPI, Basel, Switzerland. This article is an open access article distributed under the terms and conditions of the Creative Commons Attribution (CC BY) license (https:// creativecommons.org/licenses/by/ $4.0 /)$.

\begin{abstract}
Vegetarian diets have gained in popularity, especially among highly educated women, and are considered beneficial to health. Comparative studies assessing the diet of vegetarians against omnivores are rather limited and often provide ambivalent results. Therefore, this study examined the nutrient intake and nutritional quality of vegetarian and omnivorous diets in a group of 61 female students in Germany. Habitual dietary intake was evaluated using a validated graphical online food frequency questionnaire (FFQ). Differences in nutrient intakes were analyzed by MannWhitney-U-Tests. Odds Ratios (OR) were calculated for vegetarians exceeding dietary reference values (DRV) compared to omnivores. The overall nutritional quality was assessed using the HealthyEating-Index-2015 (HEI-2015). In omnivores, intakes of total energy from saturated fatty acids (SFA), monounsaturated fatty acids (MUFA), long-chain omega-3 polyunsaturated fatty acids (LC-n3-PUFA), cholesterol, sucrose, lactose, retinol, and cobalamin were significantly higher than in vegetarians. Significantly lower intakes were observed for fiber, magnesium, and beta-carotene. Significant OR were detected for total fat $(\mathrm{OR}=0.29)$, SFA $(\mathrm{OR}=0.04)$, beta-carotene $(\mathrm{OR}=4.55)$, and cobalamin $(\mathrm{OR}=0.32)$. HEI-2015 scores were higher for vegetarians than for omnivores (79 points versus 74 points) and significant differences were recorded for the HEI-2015 components dairy, seafood \& plant proteins, fatty acids, added sugars, and saturated fatty acids.
\end{abstract}

Keywords: vegetarian; omnivores; nutrient intake; food frequency questionnaire; healthy eating index; web application; personalized dietary advices

\section{Introduction}

A balanced vegetarian diet is often associated with a higher intake of vegetables, fruits, seeds, and nuts. Choosing a vegetarian diet can be associated with ethical, ecological, religious, or health motives [1]. Moreover, it has been shown that the probability of being vegetarian is positively associated with educational level and negatively associated with disposable per capita income [2]. There is evidence that a vegetarian diet supports positive health outcomes and can reduce the risk of several chronic diseases like ischemic heart disease or diabetes [3-5]. It was shown that vegetarians tend to better meet the dietary reference values (DRV) of the German Nutrition Society (DGE) than omnivores [6]. Due to a higher intake of plant-based foods and the absence of meat and fish, vegetarians were reported to have a lower energy intake and a more beneficial fat profile with lower 
intakes of cholesterol, total, and saturated fat and higher intakes in polyunsaturated fats [7]. Furthermore, the intake of vitamins associated with a plant-based diet, such as vitamin A, vitamin B1, vitamin C, vitamin E, and minerals, such as magnesium and potassium, as well as dietary fibers and secondary plant substances is often higher among vegetarians than in omnivores $[3,8,9]$.

However, a restrictive vegetarian diet may also pose health risks due to reduced intakes of certain essential nutrients, such as iron, zinc, omega-3 polyunsaturated fatty acids, riboflavin, cobalamin and calcium [1,3,9]. Though, study results on the supply of these nutrients are ambiguous and influenced by the foods excluded in the respective diets $[1,7,10,11]$. Since nutrients are consumed as a combination of foods rather than in isolation, an assessment of single nutrients may not be sufficient. Considering the interactions of nutrients and the complexity of diets, it may be useful to additionally investigate nutritional patterns by means of a diet quality score [7].

A vegetarian diet is particularly popular among young people in Germany. In 2011, approximately $4 \%$ of the German population aged 18-79 were vegetarians [12]. They were particularly prevalent in the age group of 18-29 years, of which $9 \%$ of women and 5\% of men followed a vegetarian diet. Nutritional information on vegetarian female students is scarce. In a study of dietary patterns among students in Germany, it was shown that meat consumption of male students was on average twice as high as meat consumption of female students [13]. Due to their young age and high educational level, female students form an interesting group to compare vegetarian and omnivorous diets.

To our knowledge, there are currently no studies comparing the diet between female vegetarian and non-vegetarian students in Germany. Therefore, the aim of the present analysis was to address the research questions whether female vegetarian students (1) eat healthier and (2) meet the DRV better than omnivorous students. To answer these questions, female students living in Germany were split into vegetarians including those with occasional fish consumption $(n=3)$ and omnivores based on their self-declaration within a pre-study questionnaire. Nutrient intakes and dietary quality was assessed using a novel web-based eNutri2019 food frequency questionnaire (FFQ). The latter was developed as part of the EIT-Food Quisper project. Quisper (Quality Information Services and Dietary Advice for Personalized Nutrition in Europe) is a digital platform that brings together scientifically robust personalized nutrition services and data [14,15]. The eNutri2019 FFQ and its web application were developed for assessing individuals' dietary habits as a potential basis to deliver personalized dietary advices via the Quisper Platform (https: / / quisper.eu/, accessed on 15 February 2021). The paper contributes to the scarce literature on nutrient intakes and nutritional quality of vegetarian female students who represent a large proportion of vegetarians.

\section{Materials and Methods}

\subsection{Study Design}

As part of the eNutri2019-study, a nationwide online study of 4 weeks, the food intake of 61 female university students living in Germany was examined more closely. A total of 31 vegetarians and 30 omnivores were included in the study. Ethical approval for the study was granted by the Research Ethics Committees of the Technical University Munich (approval no. 328/19S). Students were recruited via social media, and applicants were required to sign written consent forms prior to study participation. Specific medical conditions (e.g., diabetes, pregnancy) as well as specific diets (e.g., vegan, sport-specific diets) and an age below 18 years were defined as exclusion criteria. Furthermore, two study participants reporting an energy intake of more than $4500 \mathrm{kcal}$ per day were considered as over-reporters and eliminated from the dataset. After elimination of the outliers, energy intakes ranged from $706 \mathrm{kcal}$ to $3646 \mathrm{kcal}$ per day. 


\subsection{Dietary Assessment}

Habitual dietary intakes of participants were assessed using a novel self-administered, online FFQ as part of the eNutri2019-DE web application. A detailed functioning of the web application is described elsewhere [16]. The FFQ was based on the food list and portion size images of a previously validated FFQ from the Food4Me study, which was found to be reproducible across seven European countries, including Germany [17-19]. Based on the FFQ from the Food4Me study, the eNutri FFQ was further adapted with the inclusion of updated food items, portion sizes, portion size images, and the option to choose from seven different portion sizes [20]. To capture food intake frequencies, study participants could choose between the following options: $<1$ time/month (mo), 1-3 times/mo, 1 time/week (wk), 2-4 times/wk, 5-6 times/wk, 1 time/day (d), 2-3 times/d, 5-6 times/d, or $\geq 7$ times/d. The eNutri2019-FFQ covers a total of 159 food items representative of the German diet, incorporating popular country-specific foods such as traditional German breads, sausages, fermented cabbage, side dishes and desserts. Sixteen food items focused on meat consumption and therefore were skipped for the vegetarians. Calculations of nutrient intakes in the web application were based on consumed quantities and matched with the German Nutrient Database (Bundeslebensmittelschlüssel, BLS) V.3.0.1 underlying the questionnaire [21].

\subsection{Overall Dietary Quality}

The overall dietary quality of vegetarian and omnivorous subjects was evaluated based on the Healthy Eating Index-2015 (HEI-2015). The HEI-2015 was calculated in accordance with the guidelines of the U.S. Department of Health and Human-National Cancer Institute (NIH) and comprised 13 components including total fruits, whole fruits, total vegetables, greens and beans, whole grains, dairy, total protein foods, seafood and plant proteins, fatty acids, refined grains, sodium, and added sugar [22]. Based on nutrition information provided by the study participants in the FFQ, intakes of individual foods and nutrients were quantified with reference to the respective HEI-2015 components and the German Nutrient Database [21]. Depending on dietary intake, a maximum of 5 or 10 points was awarded to individual HEI-components and summed up to a total score of maximum 100 points. In orientation to the Dietary Guidelines for Americans (DGAs) [23], high HEI-2015 scores ( $>81$ points) indicate "good" nutritional quality, while low scores $(\leq 50)$ imply "poor" diets [24]. HEI-2015 values of 51-80 points are indicative of a diet that "needs improvement", with low compliance to dietary recommendations.

\subsection{Physical Activity}

The General Practice Physical Activity Questionnaire (GPPAQ) was used to assess the subjects' physical activity as part of the eNutri2019 web application. It is a validated screening tool for measuring the physical activity levels of adults (16-74 years). The results of the tool are categorized into a four-level Physical Activity Index (PAI): Active, Moderately Active, Moderately Inactive, and Inactive [25].

\subsection{Anthropometric and Socio-Economic Measurements}

Participants were provided with instructions to accurately measure their height and weight themselves and these were self-reported on the eNutri2019 web application, from which their BMI was automatically calculated. Furthermore, socio-economic data was collected via a screening questionnaire in the web application.

\subsection{Statistical Analysis}

Non-parametric Mann-Whitney-U-Tests were used to compare the estimated nutrient intakes of vegetarian and omnivorous students. Significance was tested two-tailed, applying a $5 \%$ level of significance. Odds ratios (OR) were calculated to compare the compliance of vegetarians and omnivores with the DRV. The OR indicate the chance of vegetarians exceeding the DRV compared to omnivores. OR less than 1 indicate that the chance for 
vegetarians exceeding the DRV is smaller as compared to omnivores, while OR greater than 1 indicate that vegetarians are more likely to exceed the DRV as compared to omnivores. In order to calculate the OR, a two-by-two table was used [26]. Omnivores served as reference group. To detect large deviations from the DRV, proportions of participants with a nutrient intake of more than $100 \%$ and less than $67 \%$ of the DRV were determined.

\section{Results}

\subsection{Study Participants}

The sample comprised 61 female university students living in Germany, aged 1830 years (mean $=22.5, \mathrm{SD}=4.07$ ). Thirty-one women self-reported vegetarianism and were assigned to the 'vegetarian' group, and 30 women were assigned to the 'omnivorous' group. Mean age between the vegetarian group $(25 \mathrm{y} ., \mathrm{SD}=17.7)$ and the omnivorous group $(20 \mathrm{y}$., $\mathrm{SD}=14.1)$ did not differ significantly $(p=0.40)$. Table 1 displays the main characteristics of the study participants. The majority of the students were of normal weight (BMI: $\geq 18.5$ to $<25 \mathrm{~kg} / \mathrm{m}^{2}$ ), with the omnivorous group having a slightly higher mean BMI score (BMI: $22.5 \mathrm{~kg} / \mathrm{m}^{2}$ ) than vegetarians (BMI: $21.9 \mathrm{~kg} / \mathrm{m}^{2}$ ). However, the BMI did not differ significantly between the two groups $(p=0.37)$. Applying the PAI, the majority of both groups was categorized as 'active', that is, $65 \%$ of the vegetarians and $63 \%$ of the omnivores, resulting in a non-significant difference between the two groups $(p=0.95)$. Furthermore, both groups had no significant difference in income $(p=0.87)$ : The majority of students had an income below $10.000 €$ per year (vegetarians $42 \%$, omnivores $27 \%$ ). Seventy-four of the vegetarians and $63 \%$ of the omnivores reported consuming dietary supplements such as omega-3 polyunsaturated fatty acids (vegetarians $3.2 \%$, omnivores $6.7 \%$ ), vitamin C (vegetarians $9.7 \%$, omnivores $10.0 \%$ ), vitamin D (vegetarians $25.8 \%$, omnivores $13.3 \%$ ), calcium (vegetarians $0.0 \%$, omnivores $6.7 \%$ ) and iron (vegetarians $25.8 \%$, omnivores $20 \%$ ).

Table 1. Study population characteristics.

\begin{tabular}{|c|c|c|c|c|}
\hline \multirow{2}{*}{ Variable } & \multicolumn{2}{|c|}{$\begin{array}{l}\text { Vegetarians } \\
\quad(n=31)\end{array}$} & \multicolumn{2}{|c|}{$\begin{array}{l}\text { Omnivores } \\
(n=30)\end{array}$} \\
\hline & $\begin{array}{c}\% \text { of } \\
\text { Participants }\end{array}$ & $\begin{array}{l}\text { Mean } \\
\pm \text { SD }\end{array}$ & $\begin{array}{c}\% \text { of } \\
\text { Participants }\end{array}$ & $\begin{array}{l}\text { Mean } \\
\pm \text { SD }\end{array}$ \\
\hline Age (years) & & $25.0 \pm 17.7$ & & $20.0 \pm 14.1$ \\
\hline BMI $\left(\mathrm{kg} / \mathrm{m}^{2}\right)^{\mathrm{a}}$ & & $21.9 \pm 7.0$ & & $22.5 \pm 0.8$ \\
\hline \multicolumn{5}{|l|}{ BMI classification $^{a}$} \\
\hline Underweight $\left(<18.5 \mathrm{~kg} / \mathrm{m}^{2}\right)$ & 12.9 & & 0 & \\
\hline $\begin{array}{c}\text { Normal weight }(\geq 18.5 \text { to } \\
\left.\leq 24.9 \mathrm{~kg} / \mathrm{m}^{2}\right)\end{array}$ & 77.4 & & 83.3 & \\
\hline Overweight $\left(\geq 25.0 \mathrm{~kg} / \mathrm{m}^{2}\right)$ & 9.7 & & 16.7 & \\
\hline \multicolumn{5}{|l|}{ Physical activity levels ${ }^{b}$} \\
\hline Inactive & 6.5 & & 10.0 & \\
\hline Moderately inactive & 16.1 & & 10.0 & \\
\hline Moderately active & 12.9 & & 16.7 & \\
\hline Active & 64.5 & & 63.3 & \\
\hline \multicolumn{5}{|l|}{ Place of residence } \\
\hline Northern Germany ${ }^{c}$ & 9.6 & & 13.3 & \\
\hline Western Germany ${ }^{d}$ & 19.4 & & 6.7 & \\
\hline Eastern Germany ${ }^{\mathrm{e}}$ & 19.4 & & 20.0 & \\
\hline Southern Germany ${ }^{\mathrm{f}}$ & 51.6 & & 60.0 & \\
\hline \multicolumn{5}{|l|}{ Household net income } \\
\hline Not specified & 19.4 & & 20.0 & \\
\hline No income & 19.4 & & 23.3 & \\
\hline$<10.000 € /$ year & 41.9 & & 26.7 & \\
\hline $10.000-24.999 € /$ year & 9.7 & & 10.0 & \\
\hline 25.000-39.999€/year & 6.5 & & 13.3 & \\
\hline $40.000-54.999 € /$ year & 0.0 & & 3.3 & \\
\hline$>55.000 € /$ year & 3.2 & & 3.3 & \\
\hline
\end{tabular}


Table 1. Cont.

\begin{tabular}{|c|c|c|c|c|}
\hline \multirow{2}{*}{ Variable } & \multicolumn{2}{|c|}{$\begin{array}{l}\text { Vegetarians } \\
\quad(n=31)\end{array}$} & \multicolumn{2}{|c|}{$\begin{array}{l}\text { Omnivores } \\
\quad(n=30)\end{array}$} \\
\hline & $\begin{array}{c}\% \text { of } \\
\text { Participants }\end{array}$ & $\begin{array}{l}\text { Mean } \\
\pm \text { SD }\end{array}$ & $\begin{array}{c}\% \text { of } \\
\text { Participants }\end{array}$ & $\begin{array}{l}\text { Mean } \\
\pm \text { SD }\end{array}$ \\
\hline \multicolumn{5}{|l|}{ Dietary supplementation } \\
\hline Omega-3, fish oil or cod liver oil & 3.2 & & 6.7 & \\
\hline Vitamin C & 9.7 & & 10.0 & \\
\hline Vitamin D & 25.8 & & 13.3 & \\
\hline Calcium & 0.0 & & 6.7 & \\
\hline Iron & 25.8 & & 20.0 & \\
\hline \multicolumn{5}{|c|}{$\begin{array}{l}\text { Body Mass Index (BMI) based on self-reported weight and height of study participants; }{ }^{\mathrm{b}} \text { Physical activity } \\
\text { levels are based on the General Practice Physical Activity Questionnaire (GPPAQ); }{ }^{\mathrm{c}} \text { Northern Germany includes } \\
\text { the federal states Lower Saxony, Schleswig-Holstein, Hamburg, Bremen; }{ }^{\mathrm{d}} \text { Western Germany: North Rhine- } \\
\text { Westphalia, Rhineland-Palatinate, Saarland; }{ }^{\mathrm{e}} \text { Eastern Germany: Mecklenburg-Western Pomerania, Saxony- } \\
\text { Anhalt, Brandenburg, Berlin, Thuringia, Saxony; }{ }^{\mathrm{f}} \text { Southern Germany: Bavaria, Baden-Wuerttemberg, Hesse. }\end{array}$} \\
\hline
\end{tabular}

\subsection{Nutrient Intake}

Energy and nutrient intakes from food and dietary supplements with respect to type of diet are shown in Table 2 along with the respective German DRV for nutrient intake. There were no significant differences in total energy intake between vegetarian and omnivorous students. Though, vegetarian students had a significantly lower total energy intake from fats (\%TE) compared to omnivorous students. In particular, intakes were significantly lower for saturated fatty acids (SFA), the long-chain fatty acids palmitic acid (C16:0) and stearic acid (C18:0), monounsaturated fatty acids (MUFA, \%TE), long-chain omega-3 polyunsaturated fatty acids (LC-n3-PUFA), and cholesterol. The same holds true for the intake of sucrose and lactose, as well as the (pro-)vitamins retinol and cobalamin. Conversely, the intakes of dietary fiber, magnesium, and beta-carotene were significantly higher among vegetarians.

\subsection{Odds for Meeting DRV}

Figure 1 shows the OR with their respective 95\% confidence intervals for assessed nutrients. Compared to omnivores, vegetarians had a significantly lower chance of exceeding the DRV for total energy from fat $(\mathrm{OR}=0.29, \mathrm{CI}=0.09 ; 0.86)$, saturated fatty acids (SFA: OR $=0.04, \mathrm{CI}=0.01 ; 0.35)$, and cobalamin $(\mathrm{OR}=0.32, \mathrm{CI}=0.11 ; 0.91)$. An OR of 0.29 means for example that the chance that vegetarians will exceed the DRV for fat is only 0.29 times the probability that relates to omnivores. For beta-carotene, the chance for exceeding the DRV was significantly higher for vegetarians compared to omnivores $(\mathrm{OR}=4.55, \mathrm{CI}=1.50 ; 13.76)$. For fiber and magnesium, $\mathrm{OR}$ were also very high $(\mathrm{OR}=2.49, \mathrm{CI}=0.87 ; 7.12$, and $\mathrm{OR}=4.00$, $\mathrm{CI}=0.96 ; 16.61)$, though without reaching statistical significance.

\subsection{Comparison of Nutrient Intakes with DRV}

Proportions of participants who reached more than $100 \%$ or less than $67 \%$ of the DRV were notably extreme for n6-PUFA, n3-PUFA, phosphorus, sodium, selenium, and niacin equivalents. For n6-PUFA and n3-PUFA, none of the vegetarians and omnivores exhibited an intake less than $67 \%$ of the DRV and nearly all of them exceeded the DRV (Figure 2). For phosphorus, $7 \%$ of the vegetarians and none of the omnivores had an intake less than $67 \%$ of the DRV, while $94 \%$ of the vegetarians and $90 \%$ of the omnivores surpassed the DRV. For sodium, none of the vegetarians and 3\% of the omnivores had an intake less than $67 \%$ of the DRV, and $87 \%$ of the vegetarians and $90 \%$ of the omnivores exceeded the DRV. Regarding selenium, all of the vegetarians and $93 \%$ of the omnivores had an intake less than $67 \%$ of the DRV, whereas none of the vegetarians and $3 \%$ of the omnivores exceeded the DRV. For niacin equivalents, $3 \%$ of the vegetarians and none of the omnivores had an intake less than $67 \%$ of the DRV, and $94 \%$ of the vegetarians and $97 \%$ of the omnivores surpassed the DRV. 
Table 2. Energy and nutrient intakes of female German students.

\begin{tabular}{|c|c|c|c|c|c|c|}
\hline \multirow{2}{*}{$\begin{array}{l}\text { Nutritional } \\
\text { Information }\end{array}$} & \multicolumn{2}{|c|}{$\begin{array}{l}\text { Vegetarians } \\
\quad(n=31)\end{array}$} & \multicolumn{2}{|c|}{$\begin{array}{l}\text { Omnivores } \\
\quad(n=30)\end{array}$} & \multirow{2}{*}{$\begin{array}{c}p \\
\text { Value }^{a}\end{array}$} & \multirow{2}{*}{$\begin{array}{c}\text { Dietary Reference } \\
\text { Values } \\
(\mathrm{DRV})^{\mathrm{b}} \\
\text { per Day }\end{array}$} \\
\hline & Mean \pm SD & Median (IQR) $^{c}$ & Mean \pm SD & Median (IQR) $^{c}$ & & \\
\hline Energy (kcal) & $1993.5 \pm 714.1$ & $1905.1(2594-1545)$ & $2070.9 \pm 764.2$ & $2089.4(2767-1535)$ & 0.60 & 2150 \\
\hline Energy $(\mathrm{kJ})$ & $8352.6 \pm 2989.4$ & $7975.0(10863-6482)$ & $8675.1 \pm 3201.3$ & 8750.0 (11590-6427) & 0.61 & No DRV \\
\hline Protein (\%TE) $d$ & $15.6 \pm 3.1$ & $15.2(19-13)$ & $16.2 \pm 3.3$ & $15.6(18-15)$ & 0.58 & No DRV \\
\hline Protein $(\mathrm{g})$ & $79.0 \pm 35.8$ & $72.2(105-51)$ & $84.3 \pm 37.9$ & $80.9(106-54)$ & 0.57 & 48 \\
\hline Fat (\%TE) & $29.3 \pm 6.1$ & $29.6(34-25)$ & $33.4 \pm 5.0$ & $32.1(37-30)$ & $0.01 *$ & 30 \\
\hline Fat $(\mathrm{g})$ & $67.1 \pm 33.2$ & $64.0(91-39)$ & $75.7 \pm 26.4$ & $73.3(98-60)$ & 0.16 & No DRV \\
\hline SFA $(g)^{e}$ & $24.8 \pm 14.7$ & $21.4(33-15)$ & $31.5 \pm 12.1$ & $30.6(39-23)$ & $0.02 *$ & No DRV \\
\hline SFA (\%TE) & $10.6 \pm 3.3$ & $10.6(12-9)$ & $13.9 \pm 3.0$ & $13.5(16-12)$ & $0.0001^{* * *}$ & 10 \\
\hline $\mathrm{C} 16: 0(\mathrm{~g})$ & $12.1 \pm 6.9$ & $11.0(17-7)$ & $14.6 \pm 5.4$ & $14.7(18-11)$ & $0.01 *$ & No DRV \\
\hline C18:0 (g) & $4.3 \pm 2.6$ & $3.6(6-2)$ & $6.5 \pm 2.7$ & $5.8(9-4)$ & $0.002 * *$ & No DRV \\
\hline $\operatorname{MUFA}(g)^{f}$ & $22.6 \pm 12.5$ & $19.2(31-13)$ & $25.2 \pm 8.7$ & $24.7(32-20)$ & 0.15 & No DRV \\
\hline MUFA (\%TE) & $9.7 \pm 2.7$ & $9.8(12-8)$ & $11.2 \pm 2.6$ & $10.8(12-10)$ & $0.02 *$ & No DRV \\
\hline PUFA $(g)^{g}$ & $15.3 \pm 7.0$ & $14.6(21-10)$ & $13.8 \pm 7.4$ & $13.5(17-9)$ & 0.32 & No DRV \\
\hline PUFA (\%TE) & $7.0 \pm 2.3$ & $6.0(9-5)$ & $6.0 \pm 1.9$ & $5.4(7-4)$ & 0.07 & No DRV \\
\hline n6-PUFA (g) ${ }^{h}$ & $12.9 \pm 6.4$ & $11.9(17-8)$ & $11.4 \pm 5.7$ & $11.3(15-7)$ & 0.36 & No DRV \\
\hline n6-PUFA (\%TE) & $5.9 \pm 2.2$ & $5.6(7-4)$ & $5.0 \pm 1.5$ & $4.5(6-4)$ & 0.10 & 2.5 \\
\hline n3-PUFA (g) ${ }^{\mathrm{i}}$ & $2.2 \pm 1.0$ & $2.0(2.9-1.6)$ & $2.3 \pm 1.5$ & $2.0(2.5-1.6)$ & 0.88 & No DRV \\
\hline n3-PUFA (\%TE) & $1.0 \pm 0.3$ & $1.0(1.2-0.8)$ & $0.8 \pm 0.1$ & $1.0(1.1-0.7)$ & 0.26 & 0.5 \\
\hline LC-n3-PUFA (g) j & $0.1 \pm 0.2$ & $0.1(0.2-0)$ & $0.2 \pm 0.2$ & $0.2(0.4-0.1)$ & $0.004^{* *}$ & No DRV \\
\hline Cholesterol (mg) & $196.8 \pm 157.4$ & $135.2(270-65)$ & $282.7 \pm 161.1$ & $238.3(382-168)$ & $0.013 *$ & No DRV \\
\hline Fiber $(\mathrm{g}) \mathrm{k}$ & $34.7 \pm 12.6$ & $33.1(48-27)$ & $26.3 \pm 12.4$ & $25.7(31-17)$ & $0.01 * *$ & 30 \\
\hline Starch $(\mathrm{g})$ & $138.7 \pm 58.3$ & $134.8(169-106)$ & $125.5 \pm 57.6$ & $123.8(144-81)$ & 0.38 & No DRV \\
\hline Carbohydrates (\%TE) & $46.8 \pm 6.3$ & $47.9(51-41)$ & $43.9 \pm 5.6$ & $45.2(48-41)$ & 0.05 & 50 \\
\hline Carbohydrates (g) & $243.7 \pm 80.9$ & 229.7 (299-203) & $245.4 \pm 103.4$ & $242.9(112-168)$ & 0.97 & No DRV \\
\hline Total sugars (\%TE) & $18.3 \pm 5.0$ & $18.3(22-15)$ & $19.9 \pm 6.0$ & $18.8(24-16)$ & 0.39 & No DRV \\
\hline Glucose $(\mathrm{g})$ & $19.4 \pm 7.9$ & $18.5(24-14)$ & $18.4 \pm 8.4$ & $17.5(23-12)$ & 0.56 & No DRV \\
\hline Sucrose (g) & $37.8 \pm 20.1$ & $28.5(58-22)$ & $54.8 \pm 38.7$ & $50.3(68-26)$ & $0.046^{*}$ & No DRV \\
\hline Lactose (g) & $9.6 \pm 12.0$ & $5.5(13-2)$ & $14.9 \pm 13.4$ & $10.3(19-6)$ & $0.02 *$ & No DRV \\
\hline Fructose (g) & $24.3 \pm 12.7$ & $23.4(31-13)$ & $21.0 \pm 12.0$ & $19.1(27-12)$ & 0.27 & No DRV \\
\hline Calcium (mg) & $1137.9 \pm 548.5$ & $1004.6(1440-727)$ & $1208.6 \pm 733.8$ & $1074.3(1546-715)$ & 0.91 & 1000 \\
\hline Magnesium (mg) & $524.6 \pm 188.0$ & $502.9(652-392)$ & $429.8 \pm 221.8$ & $381.0(564-294)$ & $0.03 *$ & 300 \\
\hline Phosphorus (mg) & $1579.1 \pm 672.0$ & $1436.6(2133-1099)$ & $1587.1 \pm 726.8$ & $1473.4(2248-1010)$ & 0.99 & 700 \\
\hline Sodium (mg) & $2771.8 \pm 1134.8$ & $2747.2(3622-1823)$ & $2774.6 \pm 1211.1$ & $2627.9(3260-1862)$ & 0.83 & 1500 \\
\hline Potassium (mg) & $3740.6 \pm 1267.6$ & 3665.5 (4592-2882) & $3347.4 \pm 1528.0$ & 3077.8 (4117-2162) & 0.16 & 4000 \\
\hline Iodine $(\mu \mathrm{g})$ & $130.5 \pm 62.1$ & $116.7(164-92)$ & $117.8 \pm 55.3$ & $108.6(144-75)$ & 0.37 & 200 \\
\hline Iron (mg) & $16.3 \pm 5.9$ & $15.0(22-12)$ & $13.8 \pm 6.4$ & $12.8(17-10)$ & 0.08 & 15 \\
\hline Zinc (mg) & $12.6 \pm 5.0$ & $11.4(17-9)$ & $12.2 \pm 4.9$ & $11.5(16-8)$ & 0.97 & 8.0 \\
\hline Selenium $(\mu \mathrm{g})$ & $6.8 \pm 7.0$ & $4.3(10-2)$ & $11.7 \pm 15.8$ & $7.3(12-3)$ & 0.17 & 60 \\
\hline Beta-carotene $(\mu \mathrm{g})$ & $6204.6 \pm 3595.0$ & $5224.5(7308-3653)$ & $4807.0 \pm 5147.8$ & $3228.8(4720-2278)$ & $0.01 * *$ & 4800 \\
\hline Retinol $(\mu \mathrm{g})^{1}$ & $330.2 \pm 251.0$ & $267.2(499-134)$ & $614.4 \pm 479.0$ & $486.4(747-292)$ & $0.0021 * *$ & No DRV \\
\hline Retinol equivalents $(\mu \mathrm{g})$ & $1383.3 \pm 676.6$ & $1294.6(1723-884)$ & $1455.1 \pm 1118.8$ & $1155.9(1682-795)$ & 0.56 & 800 \\
\hline Thiamine $(\mathrm{mg})$ & $1.8 \pm 1.0$ & $1.7(2.1-1.2)$ & $1.8 \pm 1.3$ & $1.4(2.3-1.0)$ & 0.82 & 1.0 \\
\hline Riboflavin (mg) & $2.1 \pm 0.9$ & $1.7(2.7-1.6)$ & $2.3 \pm 1.7$ & $2.0(2.4-1.3)$ & 0.58 & 1.1 \\
\hline Niacin $(\mathrm{mg})$ & $17.0 \pm 9.2$ & $14.3(21-11)$ & $18.0 \pm 10.5$ & $15.6(45-23)$ & 0.72 & No DRV \\
\hline Niacin equivalents (mg) & $31.6 \pm 13.1$ & $30.7(38-22)$ & $33.8 \pm 15.4$ & $30.6(45-23)$ & 0.76 & 12.5 \\
\hline Pantothenic acid (mg) & $5.4 \pm 2.4$ & $4.7(7-4)$ & $5.6 \pm 2.8$ & $5.1(6-3)$ & 0.82 & 6.0 \\
\hline Pyridoxine $(\mathrm{mg})$ & $1.9 \pm 0.8$ & $1.9(2.6-1.3)$ & $2.0 \pm 1.7$ & $1.8(2.4-1.5)$ & 0.77 & 1.4 \\
\hline Biotin $(\mu \mathrm{g})$ & $63.5 \pm 29.2$ & $63.5(84-42)$ & $56.3 \pm 27.6$ & $49.7(69-35)$ & 0.32 & $30-60$ \\
\hline Folic acid $(\mu \mathrm{g})$ & $354.6 \pm 129.0$ & $351.9(461-265)$ & $304.0 \pm 150.7$ & $287.9(342-216)$ & 0.08 & 300 \\
\hline Cobalamin $(\mu \mathrm{g})$ & $3.5 \pm 2.3$ & $3.3(5-2)$ & $5.6 \pm 3.6$ & $4.7(6-3)$ & $0.01 * *$ & 4.0 \\
\hline Ascorbic acid (mg) & $152.0 \pm 75.7$ & $138.8(192-106)$ & $136.7 \pm 69.9$ & $123.3(177-86)$ & 0.41 & 95 \\
\hline Cholecalciferol ( $\mu \mathrm{g})$ & $8.9 \pm 8.8$ & $5.9(11-4)$ & $7.8 \pm 9.5$ & $4.2(7-4)$ & 0.30 & 20 \\
\hline Alpha-Tocopherol (mg) & $13.9 \pm 5.8$ & $13.2(20-9)$ & $12.1 \pm 5.5$ & $11.3(16-9)$ & 0.28 & 12 \\
\hline Alcohol $(\mathrm{g})$ & $11.2 \pm 17.5$ & $5.4(11-0.2)$ & $6.7 \pm 6.9$ & $4.4(12-0.8)$ & 0.72 & 10 \\
\hline
\end{tabular}

a $p$ value for comparison of Medians: ${ }^{*} p \leq 0.05,{ }^{* *} p \leq 0.01,{ }^{* * *} p \leq 0.001$; Mann-Whitney-U test; ${ }^{\mathrm{b}}$ Intake recommendations according to the DGE [6] (average DRV values for female age groups 19-25 years and 25-51 years, assuming an average activity level for energy intake [PAL 1.6], an average phytate intake for zinc, and neglecting the endogenous synthesis of cholecalciferol); ${ }^{\mathrm{C}} \mathrm{IQR}$, Inter-quartile

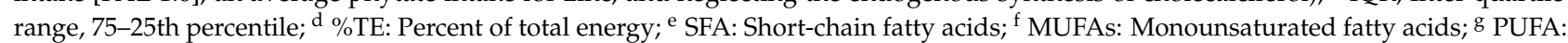
Polyunsaturated fatty acids; ${ }^{\mathrm{h}}$ Omega- 6 series of PUFA; ${ }^{i}$ Omega- 6 series of PUFA; ${ }^{j}$ LC: Long-chain; ${ }^{\mathrm{k}}$ AOAC fiber: Includes NSP and non-digestible carbohydrates; ${ }^{1} 1 \mathrm{mg}$ retinol corresponds to $1 \mathrm{mg}$ retinol equivalents. 


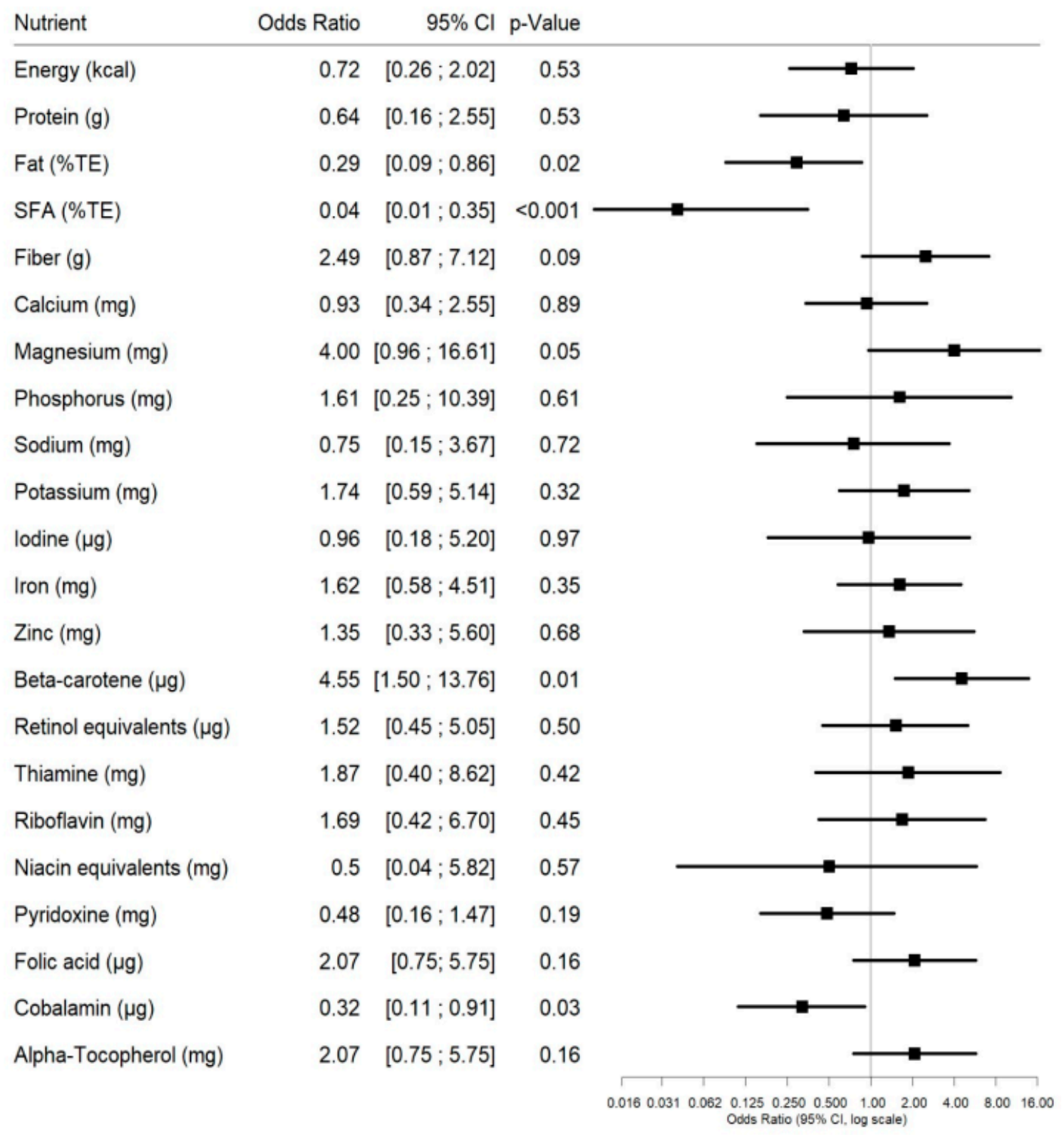

Figure 1. Forest plots showing odds ratios, 95\% confidence intervals, and $p$-values (resulting from chi-squared tests) for selected nutrients. OR indicate the chance of vegetarians exceeding the dietary reference values (DRV) compared to omnivores.

\subsection{HEI-2015}

Female vegetarian students had an insignificantly higher average HEI-2015 total score of 79 points (out of a maximum of 100 points) than their omnivorous counterparts with 74 points (Table 3). Significant differences in nutritional behavior between both groups were specifically observed for the adequacy components 'dairy', 'seafood \& plant proteins', 'fatty acids', and the moderation components 'added sugars' and 'SFA'. As compared to omnivores, vegetarians consumed on median about $50 \%$ less dairy products, $16 \%$ less added sugars, 54\% less SFA, $2 \%$ more seafood \& plant proteins, and 30\% more unsaturated fats. Looking at the maximum scores to be achieved, potential for improvement was particularly evident in vegetarians for the intakes of 'dairy', 'protein foods', 'unsaturated fats' (fatty acids), 'refined grains', 'sodium', and 'SFA'. Potential for improvement in omnivores can be found in the components 'total protein foods', 'seafood \& plant proteins', 'fatty acids', 'refined grains', 'sodium', 'added sugars', and 'saturated fats'. 

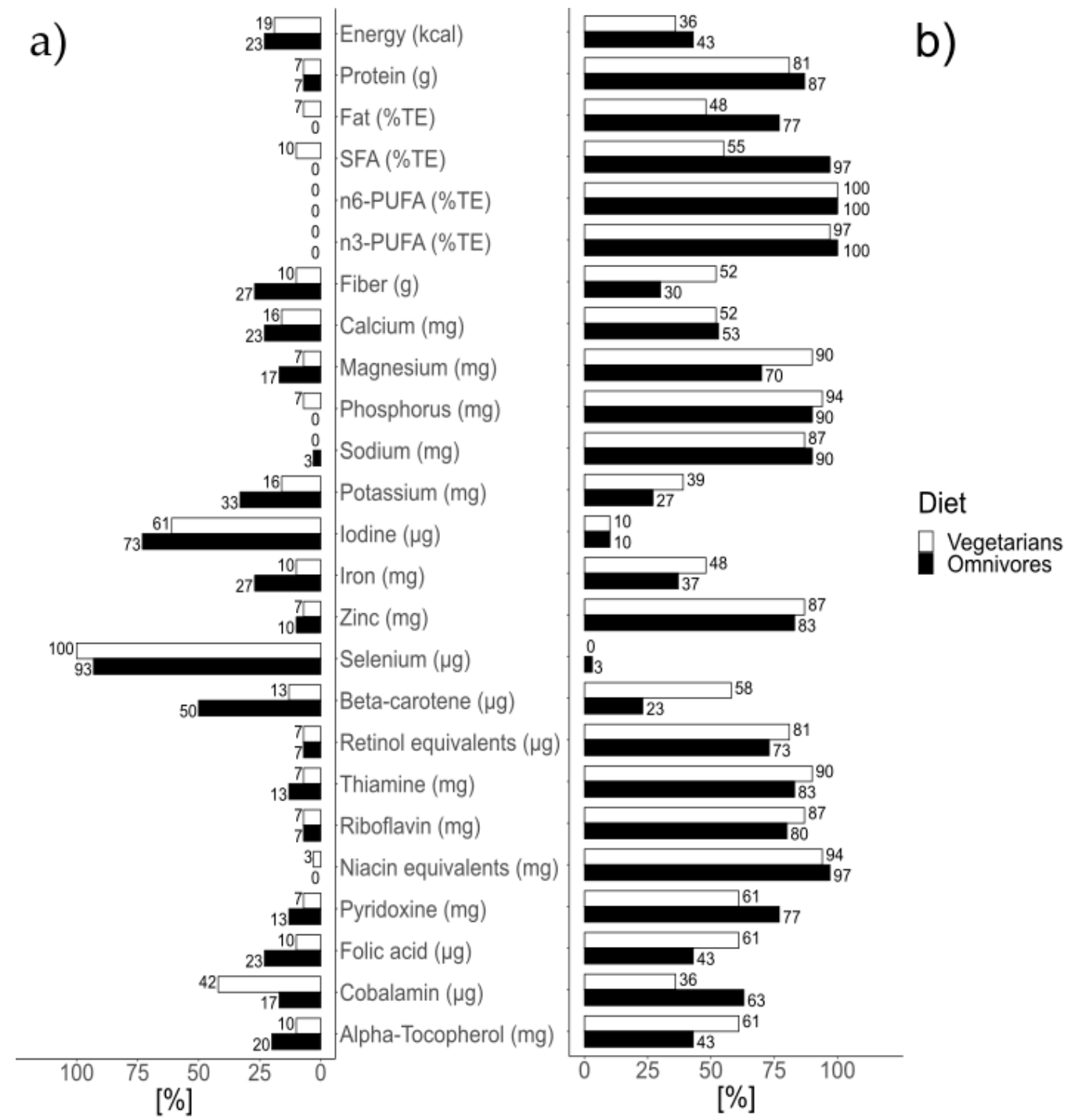

Figure 2. Proportions of participants (a) with an intake below $67 \%$ of the dietary reference values (DRV), (b) with an intake exceeding the DRV.

Table 3. Healthy Eating Index-2015 (HEI-2015) of female students.

\begin{tabular}{|c|c|c|c|c|c|c|}
\hline \multirow[t]{2}{*}{ Components } & \multirow{2}{*}{$\begin{array}{c}\text { Maximum } \\
\text { Scores }\end{array}$} & \multicolumn{2}{|c|}{$\begin{array}{l}\text { Scoring Vegetarians } \\
\qquad(n=31)\end{array}$} & \multicolumn{2}{|c|}{$\begin{array}{l}\text { Scoring Omnivores } \\
\qquad(n=30)\end{array}$} & \multirow[t]{2}{*}{$p$ Value $^{\mathrm{d}}$} \\
\hline & & Mean \pm SD & Median (IQR) ${ }^{c}$ & Mean \pm SD & Median (IQR) ${ }^{c}$ & \\
\hline \multicolumn{7}{|l|}{ Adequacy $^{\mathrm{a}}$} \\
\hline Total fruits 1 & 5 & $4.2 \pm 1.7$ & $5.0(5-5)$ & $4.3 \pm 1.5$ & $5.0(5-5)$ & 0.82 \\
\hline Whole fruits ${ }^{2}$ & 5 & $4.1 \pm 1.7$ & $5.0(5-4)$ & $4.0 \pm 1.6$ & $5.0(5-3.4)$ & 0.94 \\
\hline Total vegetables & 5 & $4.8 \pm 0.8$ & $5.0(5-5)$ & $4.5 \pm 1.3$ & $5.0(5-5)$ & 0.36 \\
\hline Greens \& Beans ${ }^{3}$ & 5 & $5.0 \pm 0.2$ & $5.0(5-5)$ & $4.6 \pm 1.2$ & $5.0(5-5)$ & 0.06 \\
\hline Whole Grains & 10 & $9.7 \pm 1.4$ & $10.0(10-10)$ & $9.3 \pm 2.1$ & $10.0(10-10)$ & 0.30 \\
\hline Dairy ${ }^{4}$ & 10 & $5.4 \pm 4.3$ & $4.8(10-1.1)$ & $8.0 \pm 3.1$ & $10.0(10-7.1)$ & $0.01 * *$ \\
\hline Total Protein Foods & 5 & $2.8 \pm 0.6$ & $2.7(3.2-2.3)$ & $2.9 \pm 0.6$ & $2.8(3.1-2.6)$ & 0.63 \\
\hline $\begin{array}{c}\text { Seafood \& } \\
\text { Plant Proteins } 5\end{array}$ & 5 & $4.8 \pm 0.7$ & $5.0(5-5)$ & $3.9 \pm 1.4$ & $4.9(5-2.6)$ & $0.001 * *$ \\
\hline Fatty Acids 6 & 10 & $6.7 \pm 2.0$ & $6.5(8-4.9)$ & $5.1 \pm 1.5$ & $4.7(6-4.1)$ & $0.001^{* *}$ \\
\hline Moderation ${ }^{\mathrm{b}}$ & & & & & & \\
\hline Refined Grains & 10 & $9.3 \pm 0.9$ & $9.7(10-8.8)$ & $9.4 \pm 0.7$ & $9.6(10-9.1)$ & 0.71 \\
\hline
\end{tabular}


Table 3. Cont.

\begin{tabular}{|c|c|c|c|c|c|c|}
\hline \multirow[t]{2}{*}{ Components } & \multirow{2}{*}{$\begin{array}{l}\text { Maximum } \\
\text { Scores }\end{array}$} & \multicolumn{2}{|c|}{$\begin{array}{l}\text { Scoring Vegetarians } \\
\qquad(n=31)\end{array}$} & \multicolumn{2}{|c|}{$\begin{array}{l}\text { Scoring Omnivores } \\
\qquad(n=30)\end{array}$} & \multirow{2}{*}{$p$ Value $^{\mathrm{d}}$} \\
\hline & & Mean \pm SD & Median (IQR) ${ }^{c}$ & Mean \pm SD & Median (IQR) $^{c}$ & \\
\hline Sodium & 10 & $6.7 \pm 2.8$ & $7.0(9.1-5)$ & $6.9 \pm 2.7$ & $7.3(9.4-5)$ & 0.92 \\
\hline Added Sugars ${ }^{7}$ & 10 & $9.3 \pm 1.1$ & $10.0(10-8.8)$ & $7.9 \pm 2.3$ & $8.4(10-7.1)$ & $0.003^{* *}$ \\
\hline Saturated Fats & 10 & $6.5 \pm 3.3$ & $6.7(9.3-5.2)$ & $3.3 \pm 2.7$ & $3.1(5.6-0.6)$ & $0.0002^{* * *}$ \\
\hline Total Score & 100 & $79.0 \pm 16.0$ & $82.5(100-66.3)$ & $73.9 \pm 17.7$ & $80.7(100-63.8)$ & 0.83 \\
\hline
\end{tabular}

${ }^{a}$ Adequacy components: Higher scores reflect higher intakes and are desirable; ${ }^{\mathrm{b}}$ Moderation components: Lower scores reflect lower intakes and are desirable; ${ }^{\mathrm{c}} \mathrm{IQR}$, Inter-quartile range, 75-25th percentile; ${ }^{\mathrm{d}} p$ value for comparison of Medians: ${ }^{*} p \leq 0.05,{ }^{* *} p \leq 0.01$, ${ }_{* * *} p \leq 0.001$; Mann-Whitney-U test; ${ }^{1}$ Includes all forms of fruit including fruit juice; ${ }^{2}$ Includes all forms of fruit except fruit juice; ${ }^{3}$ Includes legumes, beans, and peas; ${ }^{4}$ Includes all milk products (e.g., fluid milk, yogurt, cheese and fortified soy beverages); ${ }^{5}$ Includes seafood, nuts, seeds, soy products (no beverages), beans, and peas; ${ }^{6}$ Ratio of poly- and mono-unsaturated (PUFA and MUFA) to saturated fatty acids (SFA); ${ }^{7}$ Sugar added to food during preparation, processing or at table.

\section{Discussion}

\subsection{HEI-2015}

A vegetarian diet is associated with numerous positive health outcomes [27-30] and higher nutritional quality [31]. This study has shown that the dietary quality of German vegetarian students exceeded that of omnivores, which is in line with earlier results from observational studies. A cross-sectional survey on food consumption in Flemish adults in 2013, for example, reported an average HEI-2010 of 59 for vegetarians and 54 for omnivores [7]. A follow-up study with a matched-subjects design using a 3-day food diary, also found a significantly higher HEI-2010 total score for vegetarians (HEI: 54) compared to omnivores (HEI: 46) [32]. The National Health and Nutrition Examination Survey (NHANES; 2007-2012), assessing the nutritional status of the U.S. population, found average HEI-2010 scores of 73 for vegetarians and of 56 for meat eaters of different ethnicities [33]. It is worth noting that the HEI-2010 comprises 12 components and represents the predecessor version of the HEI-2015 launched in 2015. Compared to the HEI2010, the HEI-2015 additionally considers the components 'added sugars' and 'saturated fats', while disregarding the previous component of 'empty calories'. Accordingly, the results of HEI-2010 are not fully comparable to those of the HEI-2015.

Taking the European follow-up study from Clarys et al. for instance [32], considerably lower HEI-2010 scores were observed for vegetarians and omnivores as compared to the HEI-2015 in the present study. When comparing the average scores of corresponding components between the HEI-2010 and HEI-2015, the German cohort consistently scored higher except for the two components 'total protein foods' and 'sodium' and therefore translates into a higher overall HEI-2015 score. As compared to the HEI-2010, the HEI2015 has further been improved by inclusion of a legumes algorithm, designed to capture specific dietary habits such as plant-based diets more accurately [34]. Thus, the results of the HEI-2010 may deviate considerably from the HEI-2015. At the time of publication of this paper, however, there were no scientific studies available, investigating the dietary quality of vegetarians by applying the HEI-2015.

\subsection{Macronutrients}

As part of the study, the dietary intake of macro- and micronutrients was analyzed among the female student cohort. There is evidence from research that the energy intake and the BMI of vegetarians are significantly lower compared to omnivores [35-37]. Even though the current study did not reveal any differences in the average BMI between both dietary groups, discrepancies in macronutrient intakes were observed. Overall, the average energy (in kcal), protein (in g), and carbohydrate (in g) intakes of vegetarians were negligibly lower than for omnivores. However, vegetarians consumed significantly less energy from fat, less SFA, and lower amounts of cholesterol compared to non-vegetarians, which is consistent with previous results from the European Prospective Investigation into 
Cancer and Nutrition-Oxford study (EPIC-Oxford; 1993-1999), which compared the dietary intake of 4164 British female vegetarians and 11.238 meat eaters [38]. Looking at the different types of fats, significant differences were detected in the intake of the SFA palmitic acid (C16:0) and stearic acid (C18:0), which is coherent as these constitute the two major fatty acids in red meat [39]. Considerable differences were also noticed for the intake of LCn3-PUFA. Krajčovičová-Kudláčková et al. (1997) compared plasma levels of total PUFAs in younger vegetarians with omnivores, while semi-vegetarians with occasional consumption of fish or meat had significantly increased levels of the fatty acid eicospentaenoic acid (EPA; C20:5) and slightly elevated levels of docosahexaenoic acid (DHA; C22:6), while no differences were found for arachidonic acid (ARA; C20:3) and dihomo-gamma-linolenic acid (DGLA; C20:4) [40]. Even though this study considered LC-n3-PUFA as a whole without differentiating between individual fatty acids, their intakes in vegetarians were significantly lower compared to omnivores. EPA and DHA are known to be mainly derived from the consumption of oily fish and to a lesser extent from meat and dairy products [41]. Considering that $58 \%$ of the vegetarians stated in their FFQ that they had not eaten any fish at all, and taking into account that the portion sizes of those who ate fish were on average $44 \%$ smaller than in omnivores, might explain the lower LC-n3-PUFA intake of vegetarians. In terms of carbohydrates, the average intakes of both vegetarians and omnivores did not reach the German DRV of $50 \%$ of total energy. Compared to omnivores, vegetarians consumed significantly less lactose and sucrose, while their fructose intake was slightly higher. The scientific information on carbohydrate intakes by vegetarians is contradictory. A study by Bradbury et al. (2017) showed that vegetarians consumed less food containing high levels of free sugar and eat more foods high in fructose (e.g., fruits, vegetables) [42]. Slattery et al. (1991) detected lower intakes of sucrose in vegetarians, while the National Health and Nutrition Examination Survey (NHANES; 1999-2004) found higher intakes of added sugar $[43,44]$. In the current study, vegetarians consumed significantly less sugar-rich foods (e.g., soft drinks, fruit juices, sweet pastries) and dairy products compared to omnivores, thus explaining the lower sucrose and lactose intakes. The increased consumption of fruit and vegetables by vegetarians is probably related to the marginally higher fructose intake.

The median dietary fiber consumption was almost 30\% higher in vegetarians than in omnivores, mainly due to the increased consumption of whole meal cereals, fruits, and vegetables, thus exceeding the respective DRV of $>30 \mathrm{~g} / \mathrm{d}$. This is consistent with previous studies, also demonstrating a significantly higher fiber intake by approximately $15-30 \%$ among European female vegetarians [37,45].

\subsection{Micronutrients}

As for micronutrients, a significant difference in mean magnesium intake was observed between vegetarians and omnivores, both of which were well above the respective DRV of $300 \mathrm{mg} / \mathrm{d}$. Evidence suggests that diets rich in vegetables and unrefined grains are higher in magnesium than diets including meat and dairy products [46,47]. It has also been shown that a series of nutritional factors such as protein, calcium, phosphate, or vitamin $\mathrm{D}$ can evoke magnesium imbalances, while excess intake of sugar, alcohol, or salt can trigger magnesium losses through enhanced urinary excretion or interference of fiber with magnesium absorption [48].

Although the average sodium intake of vegetarians and omnivores was more than $80 \%$ above the DRV, the intake values were comparable in magnitude to Clarys et al. (2014), reporting average intake values of about $2300 \mathrm{mg} / \mathrm{d}$ for vegetarians and $3300 \mathrm{mg} / \mathrm{d}$ for omnivores [7]. A high sodium intake is associated with hypertension and coronary heart disease. Cohort studies have shown that an elevated salt intake of $5 \mathrm{~g}$ per day, corresponding to $2000 \mathrm{mg}$ of sodium, increases the overall risk of cardiovascular disease by $17 \%$ and of stroke by $23 \%$ [49].

For potassium, iodine, and selenium, both vegetarians and omnivores had on average lower intakes than the respective DRV. A Western diet is associated with lower potassium 
intakes due to reduced consumption of potassium-rich foods such as fruit and vegetables along with an increased sodium intake [50].

In view of the low concentrations of iodine and selenium in European soils and the fact that bread and dairy products constitute the principal sources of iodine in industrialized countries [51], a mild undersupply of these trace elements was to be expected.

At first glance, vegetarians showed on average a sufficient iron and zinc intake according to the DRV of $15 \mathrm{mg} / \mathrm{d}$, respectively, $8 \mathrm{mg} / \mathrm{d}$. In plant-based diets, however, it has been shown that the intestinal absorption of iron can be reduced by up to $70 \%$ and of zinc by $35 \%$ compared to meat eaters in part due to increased intakes of phytate from vegetables and whole grains, acting as an absorption inhibitor [52]. Therefore, vegetarians might be at greater risk of developing an iron-deficiency in the long-term compared to omnivores, which could be prevented by iron supplementation. Although $26 \%$ of the vegetarians of this study reported having supplemented iron, their intake barely met the intake recommendations, which might favor a deficiency in the long term. A deficit in iron intake has already been shown in a German cross-sectional study investigating the nutrition and health status of students in the city of Schwäbisch Gmünd (EGS study) [53].

Focusing on vitamins, vegetarians had significantly lower intakes of retinol as compared to omnivores. Although it is known that an adequate intake of retinol is especially problematic for ovo-lacto-vegetarians [37], the average intake of retinol equivalents in the current study substantially exceeded the DRV of $800 \mu \mathrm{g} / \mathrm{d}(1 \mu \mathrm{g}$ retinol equivalents corresponds to $1 \mu \mathrm{g}$ retinol and $6 \mu \mathrm{g}$ beta-carotene [6]). Compared to previous publications, such as the EPIC-Oxford study involving over 60,000 subjects from the UK, which reported a median intake of retinol in female vegetarians of $277 \pm 180 \mu \mathrm{g} / \mathrm{d}$, similar to this study, it was about $60 \%$ lower than for meat eaters $(654 \pm 617 \mu \mathrm{g} / \mathrm{d})$ [37]. In a representative subcohort of the British Columbia Nutrition Survey (BCNS), dietary intake of retinol equivalents was indicated with $1208 \pm 175 \mu \mathrm{g} / \mathrm{d}$ in self-reported female vegetarians $(n=106)$ and with $1186 \pm 53 \mu \mathrm{g} / \mathrm{d}$ in non-vegetarians $(n=1711)$ [54], which corresponds well with present findings. Particularly with regard to the retinol equivalent beta-carotene, vegetarians of the present study had significantly higher intakes compared to omnivores, most likely related to a higher fruit and vegetable consumption.

In contrast to omnivores, the average intake of vegetarian students investigated in this study did not meet the DRV of cobalamin set at $4 \mu \mathrm{g} / \mathrm{d}$. Given the high concentration of cobalamin in meat and animal foods (e.g., dairy products) as the main dietary sources of cobalamin [55], this result was not particularly surprising. Despite the existence of several alternate cobalamin sources (e.g., edible algae or cyanobacteria, tea leaves, fortified foods, or supplements) [56], these were of little relevance for this research. A closer look at the information provided in the FFQs of vegetarians in this study revealed dairy products, eggs, and fish to be the main sources of cobalamin in their diet. The low cobalamin intakes in vegetarians are in contrast to a study published in 2011 by Schweter et al. who examined the nutritional behavior of 102 female students in Germany using a validated 3 -day estimated dietary record and did not detect inadequate cobalamin intakes from the diet [53]. Only $36 \%$ of the vegetarians in the present study exhibited an adequate cobalamin intake according to the German DRV, while $42 \%$ of the subjects reached at least $67 \%$ of the DRV, and $22 \%$ of the subjects reported intakes even below. Compared to omnivores, this study found that vegetarians were 0.3 times less likely to exceed the DRV for cobalamin intake than omnivores. It has been widely reported that vegetarians from around the world suffer from insufficient dietary cobalamin intakes and corresponding deficiencies [57-61], which is consistent with the data presented, even though the analysis of functional biomarkers for cobalamin deficiency was not considered herein. In contrast to the German National Nutrition Survey (NVS II; 2005-2007), which detected a median dietetic cobalamin intake of $4 \mu \mathrm{g} / \mathrm{d}$ for women living in private households in the age group of 25 to 51 years $(n=3666)$, thus pointing to an adequate vitamin intake $[62,63]$, this investigation showed an insufficient cobalamin supply especially in vegetarian women. 
Moreover, the NVS II revealed inadequate intakes of folate in women (median: $257 \mu \mathrm{g} / \mathrm{d}$ ) and classified the intakes of vitamin D as critical [63]. Both vegetarians and omnivores in the current study were on average only slightly above the DRV for folate of $300 \mu \mathrm{g} / \mathrm{d}$.

Regarding vitamin D, estimates assume that about $10 \%$ of this vitamin is ingested through food, whereas approximately $90 \%$ is formed from endogenous synthesis in the human skin due to solar radiation (UV-B) [64]. In view of a DGE reference level of $20 \mu \mathrm{g} / \mathrm{d}$ for vitamin $\mathrm{D}$ without considering the endogenous synthesis, the cholecalciferol intake within the investigated student cohort by taking into account additional supplementation, was found to be adequate.

While the NVS II provided no evidence of an insufficient dietary intake of other vitamins for the German population on average, a marginal undersupply of pantothenic acid, slightly below the recommended intake of $6 \mathrm{mg} / \mathrm{d}$, was detected in female vegetarians and omnivores in the present study. To date, comprehensive data on the content of pantothenic acid in foods are limited. Primary sources of pantothenic acid are quite diverse foods such as meat, codfish, potatoes, whole grains, egg yolk, and tomato products [65]. The bioavailability of pantothenic acid from food is assumed to range from approximately 40 to $60 \%$ [62], which in the longer term could foster pantothenic acid deficiency in both omnivores and vegetarians.

For other B vitamins such as pyridoxine, biotin, folic acid, as well as ascorbic acid and alpha-tocopherol, the dietary intake did not differ significantly between vegetarians and omnivores, while the respective DRV were consistently met.

\section{Strengths and Limitations}

A major strength of this study is that it involved a very homogeneous subpopulation, all of whom shared the same gender, age structure, economic situation, as well as educational level. In addition, the focus was on younger female students pursuing a vegetarian lifestyle, on which data on nutrient intake and nutritional status in Germany are currently scarce. An added benefit is also the usage of the well-established validated graphical FFQ, which was originally developed for assessing the habitual food intake in the Food4Me study and has successfully been applied on a pan-European scale. The use of FFQs as valid tools for detecting differences in dietary intake of foods and nutrients between subpopulations is well established and scientifically accepted [66].

Furthermore, the results of this study are very promising in the context of the Quisper platform and the delivery of scientifically validated personalized nutrition (PN) advice [15]. The combined use of an FFQ, such as the eNutri2019, and a PN algorithm that provides tailored nutrition advice to consumers, can potentially have a higher impact in nudging people towards healthier (or possibly more sustainable) dietary choices like, for example, a vegetarian diet or plant-based diet. However, the approach will have to be further tested and analyzed in a real world scenario covering all the different population groups [14].

This survey is limited by the fact that the sample of the study is not representative for the general population in Germany, as only a limited number of respondents with mainly higher educational levels was considered, and a disproportionately high share of study participants were residents in Southern Germany. Although the FFQ was designed to retrospectively track the eating habits of study participants with maximum accuracy, a bias due to under- and over-reporting of subjects cannot be excluded. The large number of food items surveyed, as well as the long recall period of $1 \mathrm{month}$, might also have negatively affected the discriminatory power of the FFQ applied. Additionally, it is important to note that the present study only addressed the dietary intake of foods and nutrients, without considering interactions between food constituents that may affect bioavailability and without taking into account metabolic differences among study participants. 


\section{Conclusions}

The objective of this paper was to evaluate the food intake of female vegetarian students in Germany. The performed research demonstrates that vegetarian students tend to eat healthier diets than omnivorous students, which is reflected by an insignificantly higher HEI-2015 score in the vegetarian group. A higher intake of wholegrain products, as well as an increased intake of fruit and vegetables, for example, can be seen as factors contributing to a better HEI-2015 score. However, participants on a vegetarian diet did not meet the DRV for all nutrients. Especially for nutrients which are mainly found in animal products (e.g., cobalamin), an insufficient intake was observed on average. To efficiently prevent nutrient deficiencies, subsequent studies are needed to further evaluate the nutrient supply of vegetarians in Germany. Therefore, it is necessary to not only apply FFQs, but also to capture essential blood biomarkers that supplement insight into the actual nutrient supply in human subjects. Overall, the eNutri2019 FFQ seems to be a suitable dietary assessment tool as a basis for personalized dietary advices to individuals.

Author Contributions: Conceptualization and methodology, T.S., K.G., J.L., F.H., R.F., M.W., P.M.F. and R.Z.F.; software design, F.H., R.Z.F., J.L., R.F. and M.W.; software development, R.Z.F.; formal analysis, all; investigation, T.S., B.K. and J.B.; writing-original draft preparation, J.B., B.K. and T.S.; writing-review and editing, all; visualization, J.B. and T.S.; supervision, K.G.; project administration, K.G.; funding acquisition, K.G. All authors have read and agreed to the published version of the manuscript.

Funding: This research was funded by EIT Food, the innovation community on Food of the European Institute of Innovation \& Technology (EIT), a body of the European Union, under Horizon 2020, the EU Framework Programme for Research \& Innovation (Project ID: Quisper®2018 ID18064 \& 2019 ID19075).

Institutional Review Board Statement: The study was approved by the Ethics Committee of Technical University of Munich (date of approval: 11.11.2019).

Informed Consent Statement: Informed consent was obtained from all subjects involved in the study.

Data Availability Statement: Not applicable.

Acknowledgments: We are very grateful to Nadine Ohlhaut, who supported us in recruiting volunteers for the study and Alexandra Ganzha for her assistance in study planning. We thank the following people for their contributions to the eNutri2019-FFQ: Ariane Kehlbacher, Rachel Sutton, Guy Butcher and Nicole Dorrington. We also thank the members of the Quisper®consortium and the volunteers who participated in the study.

Conflicts of Interest: The authors declare no conflict of interest.

\section{References}

1. Craig, W.J. Nutrition concerns and health effects of vegetarian diets. Nutr. Clin. Pract. 2010, 25, 613-620. [CrossRef]

2. Lyons, S.; Tol, R.S.J.; Leahy, E. An Estimate of the Number of Vegetarians in the World; Working Paper, No. 340; Economic \& Social Research Institute (ESRI): Dublin, Ireland, 2010.

3. Fraser, G.E. Vegetarian diets: What do we know of their effects on common chronic diseases? Am. J. Clin. Nutr. 2009, 89, 1607S-1612S. [CrossRef]

4. Olfert, M.D.; Wattick, R.A. Vegetarian Diets and the Risk of Diabetes. Curr. Diab. Rep. 2018, 18, 101. [CrossRef] [PubMed]

5. Rizzo, N.S.; Jaceldo-Siegl, K.; Sabate, J.; Fraser, G.E. Nutrient profiles of vegetarian and nonvegetarian dietary patterns. J. Acad. Nutr. Diet. 2013, 113, 1610-1619. [CrossRef]

6. DGE-Deutsche Gesellschaft für Ernährung e.V. Reference Values for Nutrient Supply. Available online: https://www.dge.de/ wissenschaft/referenzwerte/ (accessed on 6 April 2020).

7. Clarys, P.; Deliens, T.; Huybrechts, I.; Deriemaeker, P.; Vanaelst, B.; De Keyzer, W. Comparison of nutritional quality of the vegan, vegetarian, semi-vegetarian, pesco-vegetarian and omnivorous diet. Nutrients 2014, 6, 1318-1332. [CrossRef]

8. Keller, M. Vegetarische und vegane Ernährung-Chancen und Risiken. Ernährung Med. 2015, 30, 55-60. [CrossRef]

9. Key, T.J.; Appleby, P.N.; Rosell, M.S. Health effects of vegetarian and vegan diets. Proc. Nutr. Soc. 2006, 65, 35-41. [CrossRef] [PubMed]

10. Barr, S.I.; Broughton, T.M. Relative weight, weight loss efforts and nutrient intakes among health-conscious vegetarian, past vegetarian and nonvegetarian women ages 18 to 50. J. Am. Coll. Nutr. 2000, 19, 781-788. [CrossRef] 
11. McEvoy, C.T.; Temple, N.; Woodside, J.V. Vegetarian diets, low-meat diets and health: A review. Public Health Nutr. 2012, 15, 2287-2294. [CrossRef]

12. Mensink, G.B.M.; Barbossa, C.L.; Brettschneider, A.-K. Prevalence of persons following a vegetarian diet in Germany. J. Health Monit. 2016, 1. [CrossRef]

13. Nössler, C.; Schneider, M.; Carlsohn, A.; Lührmann, P. Ernährungsmuster und Nährstoffzufuhr von Studentinnen und Studenten. Aktuelle Ernährungsmed. 2016, 41. [CrossRef]

14. Goossens, J.; Mathijssen, G.; Simillion, H.; Finglas, P.; Segovia-Lizano, D. Introducing personalized nutrition services in a behavioural motivation concept for connected food service environments. Agro Food Ind. Hi Tech 2020, $31,48$.

15. Segovia-Lizano, D.; Goossens, J.; Astley, S.; Berry RFinglas, P. Quisper and development of a personalized nutrition community. Agro Food Ind. Hi-Tech 2020, 31, 36.

16. Fallaize, R.; Weech, M.; Zenun Franco, R.; Kehlbacher, A.; Hwang, F.; Lovegrove, J. The eNutri app-Using diet quality indices to deliver automated personalised nutrition advice. Agro Food Ind. Hi-Tech 2020, 31, 44-47.

17. Fallaize, R.; Forster, H.; Macready, A.L.; Walsh, M.C.; Mathers, J.C.; Brennan, L.; Gibney, E.R.; Gibney, M.J.; Lovegrove, J.A. Online dietary intake estimation: Reproducibility and validity of the Food4Me food frequency questionnaire against a 4-day weighed food record. J. Med. Internet Res. 2014, 16, e190. [CrossRef] [PubMed]

18. Forster, H.; Fallaize, R.; Gallagher, C.; O’Donovan, C.B.; Woolhead, C.; Walsh, M.C. Online dietary intake estimation: The Food4Me food frequency questionnaire. J. Med. Internet Res. 2014, 16, e150. [CrossRef]

19. Marshall, S.J.; Livingstone, K.M.; Celis-Morales, C.; Forster, H.; Fallaize, R.; O'Donovan, C.B. Reproducibility of the Online Food4Me Food-Frequency Questionnaire for Estimating Dietary Intakes across Europe. J. Nutr. 2016, 146, 1068-1075. [CrossRef] [PubMed]

20. Zenun Franco, R.; Fallaize, R.; Lovegrove, J.A.; Hwang, F. Online dietary intake assessment using a graphical food frequency app (eNutri): Usability metrics from the EatWellUK study. PLoS ONE 2018, 13, e0202006. [CrossRef]

21. German Nutrient Data Base. Max Rubner-Institut, Bundesforschungsinstitut für Ernährung und Lebensmittel (MRI), Karlsruhe. Available online: https:/ /blsdb.de/ (accessed on 2 April 2020).

22. NIH-National Cancer Institute. The Healthy Eating Index. Available online: https://epi.grants.cancer.gov/hei/populationratio-method.html (accessed on 4 April 2020).

23. U.S. Department of Health and Human Services. 2015-2020 Dietary Guidelines for Americans; USDA: Washington, DC, USA, 2015. Available online: https:/ / health.gov/our-work/food-nutrition/2015-2020-dietary-guidelines (accessed on 2 April 2020).

24. Basiotis, P.P.; Carlson, A.; Gerrior, S.A.; Juan, W.Y.; Lino, M. The Healthy Eating Index: 1999-2000. U.S. Department of Agriculture, Center for Nutrition Policy and Promotion. CNPP-12. 2002. Available online: https://fns-prod.azureedge.net/sites/default/ files/healthy_eating_index/HEI99-00report.pdf (accessed on 2 April 2020).

25. GPPAQ-Guidance. The General Practice Physical Activity Questionnaire (GPPAQ) - A Screening Tool to Assess Adult Physical Activity Levels Within Primary Care. NHS, 2009. Available online: https://assets.publishing.service.gov.uk/government/ uploads/system/uploads/attachment_data/file/192453/GPPAQ_-_guidance.pdf (accessed on 1 April 2020).

26. Bland, J.M.; Altman, D.G. Statistics notes. The odds ratio. BMJ 2000, 320, 1468. [CrossRef] [PubMed]

27. Huang, T.; Yang, B.; Zheng, J.; Li, G.; Wahlqvist, M.L.; Li, D. Cardiovascular disease mortality and cancer incidence in vegetarians: A meta-analysis and systematic review. Ann. Nutr. Metab. 2012, 60, 233-240. [CrossRef] [PubMed]

28. Kahleova, H.; Pelikanova, T. Vegetarian Diets in the Prevention and Treatment of Type 2 Diabetes. J. Am. Coll. Nutr. 2015, 34, 448-458. [CrossRef]

29. Turner-McGrievy, G.; Harris, M. Key elements of plant-based diets associated with reduced risk of metabolic syndrome. Curr. Diab. Rep. 2014, 14, 524. [CrossRef] [PubMed]

30. Yokoyama, Y.; Nishimura, K.; Barnard, N.D.; Takegami, M.; Watanabe, M.; Sekikawa, A. Vegetarian diets and blood pressure: A meta-analysis. JAMA Intern. Med. 2014, 174, 577-587. [CrossRef] [PubMed]

31. Parker, H.W.; Vadiveloo, M.K. Diet quality of vegetarian diets compared with nonvegetarian diets: A systematic review. Nutr. Rev. 2019, 77, 144-160. [CrossRef]

32. Clarys, P.; Deriemaeker, P.; Huybrechts, I.; Hebbelinck, M.; Mullie, P. Dietary pattern analysis: A comparison between matched vegetarian and omnivorous subjects. Nutr. J. 2013, 12, 82. [CrossRef]

33. Conrad, Z.; Karlsen, M.; Chui, K.; Jahns, L. Diet quality on meatless days: National Health and Nutrition Examination Survey (NHANES), 2007-2012. Public Health Nutr. 2017, 20, 1564-1573. [CrossRef]

34. Krebs-Smith, S.M.; Pannucci, T.E.; Subar, A.F.; Kirkpatrick, S.I.; Lerman, J.L.; Tooze, J.A. Update of the Healthy Eating Index: HEI-2015. J. Acad. Nutr. Diet. 2018, 118, 1591-1602. [CrossRef] [PubMed]

35. Davey, G.K.; Spencer, E.A.; Appleby, P.N.; Allen, N.E.; Knox, K.H.; Key, T.J. EPIC-Oxford: Lifestyle characteristics and nutrient intakes in a cohort of 33883 meat-eaters and 31546 non meat-eaters in the UK. Public Health Nutr. 2003, 6, 259-269. [CrossRef] [PubMed]

36. Levin, N.; Rattan, J.; Gilat, T. Energy intake and body weight in ovo-lacto vegetarians. J. Clin. Gastroenterol. 1986, 8, 451-453. [CrossRef]

37. Nebl, J.; Schuchardt, J.P.; Wasserfurth, P.; Haufe, S.; Eigendorf, J.; Tegtbur, U. Characterization, dietary habits and nutritional intake of omnivorous, lacto-ovo vegetarian and vegan runners-A pilot study. BMC Nutr. 2019, 5, 51. [CrossRef] 
38. Sobiecki, J.G.; Appleby, P.N.; Bradbury, K.E.; Key, T.J. High compliance with dietary recommendations in a cohort of meat eaters, fish eaters, vegetarians, and vegans: Results from the European Prospective Investigation into Cancer and Nutrition-Oxford study. Nutr. Res. 2016, 36, 464-477. [CrossRef]

39. Fink-Gremmels, J. Nutrition, residues and health. Fleischwirtsch. Int. 1993, 2, 3-13.

40. Krajcovicová-Kudlácková, M.; Simoncic, R.; Béderová, A.; Klvanová, J. Plasma fatty acid profile and alternative nutrition. Ann. Nut. Metab. 1997, 41, 365-370. [CrossRef]

41. Tur, J.A.; Bibiloni, M.M.; Sureda, A.; Pons, A. Dietary sources of omega 3 fatty acids: Public health risks and benefits. Br. J. Nutr. 2012, 107, 23-52. [CrossRef]

42. Bradbury, K.E.; Tong, T.Y.N.; Key, T.J. Dietary intake of high-protein foods and other major foods in meat-eaters, poultry eaters, fish-eaters, vegetarians, and vegans in UK Biobank. Nutrients 2017, 9, 1317. [CrossRef]

43. Farmer, B.; Larson, B.T.; Fulgoni, V.L.; Rainville, A.J.; Liepa, G.U. A vegetarian dietary pattern as a nutrient-dense approach to weight management: An analysis of the national health and nutrition examination survey 1999-2004. J. Am. Diet. Assoc. 2011, 111, 819-827. [CrossRef] [PubMed]

44. Slattery, M.L.; Jacobs, D.R.; Hilner, J.E.; Caan, B.J.; Van Horn, L.; Bragg, C. Meat consumption and its associations with other diet and health factors in young adults: The CARDIA study. Am. J. Clin. Nutr. 1991, 54, 930-935. [CrossRef] [PubMed]

45. Newby, P.K.; Tucker, K.L.; Wolk, A. Risk of overweight and obesity among semivegetarian, lactovegetarian, and vegan women. Am. J. Clin. Nutr. 2005, 81, 1267-1274. [CrossRef]

46. Deriemaeker, P.; Aerenhouts, D.; Hebbelinck, M.; Clarys, P. Nutrient based estimation of acid-base balance in vegetarians and non-vegetarians. Plant Foods Hum. Nutr. 2010, 65, 77-82. [CrossRef]

47. Marier, J.R. Magnesium content of the food supply in the modern-day world. Magnesium 1986, 5, 1-8.

48. Seelig, M.S. Magnesium requirements in human nutrition. Magnes. Bull. 1981, 3, $26-47$.

49. Strazzullo, P.; D’Elia, L.; Kandala, N.-B.; Cappuccio, F.P. Salt intake, stroke, and cardiovascular disease: Meta-analysis of prospective studies. BMJ 2009, 339, b4567. [CrossRef] [PubMed]

50. Weaver, C.M. Potassium and health. Adv. Nutr. 2013, 4, 368S-377S. [CrossRef] [PubMed]

51. Zimmermann, M.B. Iodine deficiency in industrialized countries. Clin. Endocrinol. 2011, 75, 287-288. [CrossRef]

52. Hunt, J.R. Bioavailability of iron, zinc, and other trace minerals from vegetarian diets. Am. J. Clin. Nutr. 2003, 78, 633S-639S. [CrossRef]

53. Schweter, A.; Heimgärtner, C.; Jäger, J.; Schleicher, K.; Witetschek, S.; Lührmann, P. Ernährungsverhalten und körperliche Aktivität von Schwäbisch Gmünder Studentinnen. Prävent. Gesundh. 2011, 6, 270-276. [CrossRef]

54. Bedford, J.L.; Barr, S.I. Diets and selected lifestyle practices of self-defined adult vegetarians from a population-based sample suggest they are more "health conscious". Int. J. Behav. Nutr. Phys. Act. 2005, 2, 4. [CrossRef]

55. Gille, D.; Schmid, A. Vitamin B12 in meat and dairy products. Nutr. Rev. 2015, 73, 106-115. [CrossRef]

56. Watanabe, F. Vitamin B12 sources and bioavailability. Exp. Biol. Med. 2007, 232, 1266-1274. [CrossRef]

57. Gilsing, A.M.J.; Crowe, F.L.; Lloyd-Wright, Z.; Sanders, T.A.B.; Appleby, P.N.; Allen, N.E. Serum concentrations of vitamin B12 and folate in British male omnivores, vegetarians and vegans: Results from a cross-sectional analysis of the EPIC-Oxford cohort study. Eur. J. Clin. Nutr. 2010, 64, 933-939. [CrossRef]

58. Herrmann, W.; Geisel, J. Vegetarian lifestyle and monitoring of vitamin B-12 status. Clin. Chim. Acta 2002, 326, 47-59. [CrossRef]

59. Kwok, T.; Cheng, G.; Woo, J.; Lai, W.K.; Pang, C.P. Independent effect of vitamin B12 deficiency on hematological status in older Chinese vegetarian women. Am. J. Hematol. 2002, 70, 186-190. [CrossRef] [PubMed]

60. Mann, N.J.; Li, D.; Sinclair, A.J.; Dudman, N.P.; Guo, X.W.; Elsworth, G.R. The effect of diet on plasma homocysteine concentrations in healthy male subjects. Eur. J. Clin. Nutr. 1999, 53, 895-899. [CrossRef] [PubMed]

61. Refsum, H.; Yajnik, C.S.; Gadkari, M.; Schneede, J.; Vollset, S.E.; Orning, L. Hyperhomocysteinemia and elevated methylmalonic acid indicate a high prevalence of cobalamin deficiency in Asian Indians. Am. J. Clin. Nutr. 2001, 74, 233-241. [CrossRef] [PubMed]

62. Bechthold, A.; Albrecht, V.; Leschik-Bonnet, E.; Heseker, H. Beurteilung der Vitaminversorgung in Deutschland. Teil 1: Daten zur Vitaminzufuhr. Ernährungs Umsch. 2012, 59, 324-336.

63. Bechthold, A.; Albrecht, V.; Leschik-Bonnet, E.; Heseker, H. Beurteilung der Vitaminversorgung in Deutschland. Teil 2: Kritische Vitamine und Vitaminzufuhr in besonderen Lebenssituationen. Ernährungs Umsch. 2012, 59, 396-401.

64. Holick, M.F. Vitamin D deficiency. N. Engl. J. Med. 2007, 357, 266-281. [CrossRef] [PubMed]

65. Walsh, J.H.; Wyse, B.W.; Hansen, R.G. Pantothenic acid content of 75 processed and cooked foods. J. Am. Diet. Assoc. 1981, 78, 140-144.

66. Molag, M.L.; De Vries, J.H.; Ocké, M.C.; Dagnelie, P.C.; Van den Brandt, P.A.; Jansen, M.C.J.F. Design characteristics of food frequency questionnaires in relation to their validity. Am. J. Epidemiol. 2007, 166, 1468-1478. [CrossRef] 